\title{
Adult Educators Adopting Technology in Their Classrooms Through Innovation, Collaboration, and Inquiry
}

Jennifer Kobrin, University of Pennsylvania

Peta-Gaye Nicole Bullock, PowerCorpsPHL

Jillian Gierke, Garces Foundation

Charlie Heil, HIAS PA

\begin{abstract}
Technology is a critical resource in adult education, yet opportunities for ongoing training and support for practitioners are few. This article explores an inquiry-based, collaborative professional development initiative focused on technology adoption, sharing the firsthand accounts of three adult education teachers who participated. Perceived benefits included ways for learners to build English language and reading comprehension skills, and adjustments in teaching practices to encourage increased peercentered learning. Strategies for technology adoption are also provided through the teachers' examples, which may be useful for practitioners new to technology integration.
\end{abstract}

Keywords: adult basic education, technology adoption, professional development, digital literacy

Many adult educators are turning to technology as a resource that has potential for anywhere/ anytime learning opportunities, meeting learners' diverse goals, and supporting digital literacy. However, using any new technology in the classroom can also present unexpected obstacles, from technical glitches to learners not participating as intended. More opportunities for ongoing professional development and information about best practices for technology are needed in the field (Rosen \& Vanek, 2017).
In Philadelphia, the Office of Adult Education (OAE) worked since 1983 to provide professional development and technical assistance to adult education programs. ${ }^{1}$ In 2017, we received funding to implement the PHL Technology in Adult Education Initiative. The project ran for 18-months and was structured around three 90-day sprints for the nine adult education practitioners who participated to completion, with a focus on ongoing peer collaboration. We also provided support as practitioners developed

1 As of Summer 2020, adult education services are now a part of the City of Philadelphia, Office of Children and Families. 
research questions, collected and analyzed data, and wrote reflections based on their findings.

A collaborative, inquiry-based approach has been used successfully as a way for teachers to advance their practice related to technology (Hobbs \& Coiro, 2019). To further highlight the learning opportunities that accrue by sharing knowledge among participants, we employed a communities of practice approach. Communities of practice have been used widely in educational settings and emphasize learning and knowledge creation as a social process (Lave \& Wenger, 1991; Wenger, 1998). The research aspect of the project was inspired by the idea of practitioner inquiry, which focuses on knowledge generated by practitioners in their practice (Cochran-Smith \& Lytle, 2009). We also drew from general best practices in K-12 professional development, including active learning techniques and time for collaboration and reflection (Darling-Hammond et al., 2017). Finally, certain logistical aspects were informed by a similar initiative (Illinois Digital Learning Lab, 2018).

Participants were teachers and administrators from programs focused on ESL, workforce development, and high school equivalency. The initial phase included recruitment and onboarding, where participants self-selected into teams based on themes they identified: Leveraging Technology Inside the Classroom (1), Technology as a Resource Outside the Classroom (2), and Supporting Adult Learners' Retention (3). During this phase, team members also collaborated on problem statements and research questions, and participants chose a specific technology project. Implementation was structured around the three sprints as well as quarterly facilitated meetings at OAE for the entire group and monthly meetings of smaller teams. While the sprints created a structured opportunity to iterate with technology over time, the meetings offered a space for participants to troubleshoot, learn from each other's experiences, and collectively analyze data.

The next three sections were written by teachers who participated in the initiative. Each example illustrates how different aspects of the model were applied to integrate technology in a unique context, including mind maps to support informational interviews in a youth workforce development program, the use of texting for new immigrants and refugees, and blended learning for busy restaurant workers.

\section{Mind Maps as a Tool for Critical Thinking (Peta-Gaye Nicole Bullock, Team 1)}

I am the training and curriculum manager at PowerCorpsPHL, a workforce development program serving 18-28 year olds disconnected from work or school. I became interested in the PHL Technology in Adult Education Initiative because many of the young people we serve do not have strong digital literacy skills or access to technology. I work with the fellows, PowerCorps members in their second phase of the program, and wanted to improve how digital literacy, digital communication, and problem solving were incorporated in the $21^{\text {st }}$ century work readiness training we provide. Additionally, it was helpful to work with peers in Philadelphia facing the same challenges, who could offer insight on creative solutions to integrating technology while reinforcing work-ready skills.

Early in the project, my team decided to focus on how technology could support critical thinking. Therefore, I chose to rely on the Google search engine to help our fellows complete digital mind maps, find professionals in their field of interest, and contact those professionals over email to 
request an informational interview. By having them rely primarily on the internet, I hoped to increase their autonomy and ability to solve onthe-job problems. For the informational interview project, I held bi-weekly meetings with the fellows where they are given an agenda and work independently to further their digital literacy.

One of the key lessons that emerged centered around the mind maps the fellows created. The structure of the sprints and the opportunity to get feedback from my team helped me refine my approach. In sprint one, I found the mind maps lacked creativity due to the rigid structure I put in place. During this sprint, I walked the fellows through the process of creating an organizational chart using Microsoft Word, leaving them with only this format to complete the mind maps and asking them to work independently. In sprints two and three, having reflected on the previous sprint and getting feedback from my team, I decided to give them a few lines of written instructions that included the word "mind map," and encouraged them to use Google or other internet resources to find examples, and collaborate with peers. I found that many of the fellows decided to use the chart feature within Google Docs. It was exciting to see their thought process in those mind maps, as the freedom of Google Docs allowed them to be creative and thus produce more detailed mind maps.

A key takeaway in working with adult learners is to find a balance in the amount of support and flexibility provided. This experience also reinforced that I should never assume what learners know (or do not know). Instead, I used a pre- and post-survey that assessed fellows' critical thinking and problem-solving skills, along with their technology use, to ascertain their digital skills and lend support as needed. My advice is to provide adult learners with space to show what they know, challenge them to use the digital tools to which they have access, and provide support when they are struggling. Recently the alumni speaker for our graduation credited his current full-time employment as a youth advocate to the informational interview project that is now a permanent part of the fellow curriculum as a result of my participation in the project.

\section{Using Text Messages to Boost Learning Outside the Classroom (Charlie Heil, Team 2)}

As an English as a Second Language (ESL) instructor at HIAS PA, a non-profit agency providing legal and social services to refugees, asylees and immigrants in Philadelphia, I work primarily with beginner-proficiency learners of English, many of them at preliterate or emergent literacy levels in both English and their native languages. Figuring out ways to integrate digital technology into a class that is completely analogue can seem intimidating, and it is easy to procrastinate without deadlines or deliverables. By participating in this initiative, I had a support network of peers and a structure including sprints and deadlines.

In order to understand their needs better, I observed and talked to my learners about how they were using technology. I noticed that about half had difficulty using their phones to read and respond to text messages, and at least one learner had never used the text feature. This lack of experience with technology can cause challenges for my learners in their daily lives. I felt it was important to add a focus on digital literacy through sending and receiving text messages. I sent out short "homework" questions based on what we had covered in class; for example, "What is she wearing?" or "What's this?" with a picture of a vocabulary word. Learners could choose 
whether to reply to the question, and answers were reviewed in class for accuracy. For learners with little print-based literacy, responding to texts could also help them learn the alphabet and become familiar with typing.

As with teaching grammar, it is easy to make assumptions about what beginner learners know. In the case of text messages, I quickly learned that I needed to deconstruct the smaller steps involved in sending a text message, versus assuming my learners would just figure it out. My team faced similar challenges, so we worked together to come up with solutions. For example, in sprint one, the average engagement rate was around $20 \%$. I brought this concern to my peers, who were also experiencing variable participation levels among their learners, and we brainstormed ideas to increase engagement. Thanks to their input, in sprint two, I started checking answers in class, which proved to be a motivating factor. I also prepared a board to track learner participation that I would display at the end of class, giving stars as a reward for completed assignments. I noticed after I started using this board, several learners responded more consistently. Participation by the end of the sprint averaged approximately $40 \%$. Learners who made the effort to engage regularly in the assignments saw significant gains in their response rate and accuracy of replies. One success story was a learner who had never sent a text message becoming one of the most active and consistent participants.

It is important to encourage literacy in all areas: reading and writing on paper and on screen; using pens and pencils, keyboards, and touchscreens; and turning pages and scrolling. It is also important not to make assumptions, given that technology often entails a complex series of steps, especially for individuals who are new to it.
Since the initiative came to an end, we have made digital literacy a component inside and outside the classroom. Every class includes at least one activity where students participate by using their phones, with teachers on hand to help. Communication with students for administrative and pedagogical purposes outside the classroom utilizes a blend of text messaging, WhatsApp, and phone calls.

\section{Engaging with Google Classroom in an ESL Book Club (Jillian Gierke, Team 3)}

English for the Restaurant and Everyday Living (EREL) is an adult ESL program supported by the Garces Foundation in South Philadelphia. Learners are recent immigrants from Central and South America between 18-60 years of age seeking better economic opportunities. With most of our learners finding employment in the restaurant industry, our biggest challenge is retention. Frequent changes in work schedules prevent learners from attending classes.

With the opportunity to work on a team with educators also focused on retention, I was able to talk about these challenges and further refine my individual research question. With the support of my team, I decided to focus on online learning options using Google Classroom. I chose to offer an in-person and online blended course for our advanced book club. Previously, the class was only offered in-person for 1 hour per week, and I noticed additional time was needed to scaffold learners towards a more profound understanding of the text. With the addition of Google Classroom, learners can stay connected between classes through online discussion. Therefore, in theory, learners in the book club would attend in-person class meetings with a solid understanding of what took place in the assigned 50 pages of reading and be more prepared to engage in discussions. 
During the first sprint, I designated Classroom as a virtual place for learners to have discussions and ask questions outside class. I did not mandate that my learners use Classroom but simply offered it as a resource. I posted resources, notes from class, and videos related to the reading. Unfortunately, learners did not post questions, comment on, or initiate discussion on their own. Needless to say, I was discouraged by these results; nonetheless, after checking in with my team, I learned that a teammate also using Google Classroom had a similar experience.

To increase participation during the second sprint, we decided it was essential to post mandatory weekly assignments related to the assigned reading. This approach was far more successful in encouraging participation. Before weekly inperson meetings, all learners completed a brief multiple-choice quiz on the reading, responded to a writing prompt, and then they responded to their classmates' writing. With this routine, learners were clarifying concepts such as plot before coming to class and, if absent, could participate online.

For the third sprint, I used Classroom with an advanced language class that meets twice weekly. Classroom was used to post content and assignments to review lessons and also to prepare for the next class. Since I did not ask learners to complete nearly 50 pages of reading in addition to the assignments posted on Classroom, assignment completion rates with this class were much higher than with the advanced book club.

Participation in this project over the last 2 years has prepared me to continue meeting the needs of our learners amidst a global health crisis. In response to the COVID-19 pandemic, I transferred all of our classes to Google Classroom. Students have the option to enroll themselves in the appropriate level class in addition to other electives such as book club, a ServSafe food handler test prep course, and others. This is a monumental experience for our learners to have the opportunity to view online learning as a necessity rather than an additional option. Despite such uncertainty in challenging times, there is hope in this experience.

\section{Conclusion}

The importance of professional development in adult education rooted in ongoing collaboration and inquiry is underscored by these examples. In addition to strategies to assist with specific issues related to implementation, each practitioner learned that many of the challenges they faced were shared by peers, and through this process received encouragement and motivation to continue. The research aspect of the project also helped individuals to refine their area of interest by developing research questions and uncover assumptions through collecting and reflecting on data. It is critical to consider the unique challenges related to technology adoption, and the need for more professional development to be ongoing, experiential, collaborative, inquiry-based, and practitioner-centered. We hope the information provided can benefit both administrators who wish to implement more effective professional development, and educators adopting technology in their classrooms. 


\section{References}

Cochran-Smith, M., \& Lytle, S. L. (2009). Inquiry as stance: Practitioner research for the next generation. Teachers College Press.

Darling-Hammond, L., Hyler, M. E., \& Gardner, M. (2017). Effective teacher professional development. Learning Policy Institute. https://static1.squarespace.com/ static/56b90cb101dbae64ff707585/t/5ade348e70a6ad62 4d417339/1524511888739/NO LIF 1.PDF

Hobbs, R., \& Coiro, J. (2019). Design features of a professional development program in digital literacy. Journal of Adolescent and Adult Literacy, 62(4), 401-409.
Illinois Digital Learning Lab. (2018). Illinois Digital Learning Lab field report. https://drive.google.com/ file/d/1t5ltCHqiC3E2hBbuT1B1Om49krm9OeBf/view

Lave, J., \& Wenger, E. (1991). Situated learning: Legitimate peripheral participation. Cambridge University Press.

Rosen, D. J., \& Vanek, J. B. (2017). Technology for innovation and change in adult basic skills education. New Directions for Adult and Continuing Education, (155), 51-60.

Wenger, E. (1998). Communities of practice: Learning, meaning, and identity. Cambridge University Press. 